\title{
INFLUÊNCIA DO AGROTÊXTIL SOBRE A DENSIDADE POPULACIONAL DE Monosporascus cannonballus EM SOLO CULTIVADO COM MELANCIA (Citrullus lanatus) ${ }^{1}$
}

\section{Influence of the row cover on the population density of Monosporascus cannonballus in soil cultivated with watermelon (Citrullus lanatus)}

\author{
Erika Valente de Medeiros², Ernildo César da Silva Serafim³ ${ }^{3}$, Leilson Costa Granjeiro ${ }^{4}$, \\ José Espínola Sobrinho ${ }^{5}$, Maria Zuleide de Negreiros ${ }^{4}$, Rui Sales Júnior ${ }^{4}$
}

\begin{abstract}
RESUMO
O fungo Monosporascus cannonballus é um importante patógeno radicular que ocasiona a síndrome denominada colapso em cucurbitáceas. No presente trabalho, objetivou-se, avaliar os efeitos da cobertura de planta com agrotêxtil branco de $15 \mathrm{~g} \mathrm{~m}^{-2}$, sobre a densidade populacional de M. cannonballus, em solo cultivado com melancia [Citrullus lanatus (Thumb.) Matsu \& Nakai]. O delineamento experimental utilizado foi o de blocos casualizados em esquema de parcelas subdivididas, com três repetições. As parcelas foram constituídas por utilização ou não do agrotêxtil e as subparcelas pelas épocas de coleta de solo $(0,12,24,36,48$ dias após o transplantio). As variáveis analisadas foram densidade de ascósporos, temperatura do solo e do ar. Não houve influência da utilização da cobertura de agrotêxtil perante a densidade de ascósporos de $M$. cannonballus, no solo cultivado com melancia, mesmo que tenha proporcionado redução nas temperaturas médias do ar e do solo, sendo uma alternativa eficaz de manejo, na produção da melancia Mickylee.
\end{abstract}

Termos para indexação: Citrullus lanatus, extração de ascósporos, inóculo, temperatura.

\begin{abstract}
The fungus M. cannonballus is an important root pathogen that causes collapse in cucurbitaceas. The present work had as objective to evaluate the effect of the row cover with white polypropylene of $15 \mathrm{~g} \mathrm{~m}^{-2}$ on the population density of M.cannonballus in soil cultivated with watermelon [Citrullus lanatus (Thumb.) Matsu \& Nakai]. The experimental design was of randomized blocks using parcels subdivided scheme with three replications. The parcels consisted of use or not row cover and subparcelas through the time of soil collected $(0,12,24,36,48$ days after the transplanting). The variables evaluates were ascospores density, soil temperature and air temperature. There was not influence of the characteristics gotten for the row cover before the ascospores density of $M$. cannonballus, in the soils cultivated with watermelon and proportioning reduction of soil temperature means and air temperature means, being efficient alternative in the Mickylee watermelon production.
\end{abstract}

Index terms: Citrullus lanatus, ascospores extraction, inoculum, temperature.

(Recebido em 10 de janeiro de 2007 e aprovado em 21 de novembro de 2007)

\section{INTRODUÇÃO}

A melancieira (Citrullus lanatus (Thumb) Matsu e Nakai) é uma das olerícolas mais apreciadas em todo o mundo. No Brasil, possui uma área plantada de 78232 hectares, sendo produzida praticamente em todos os estados, destacando-se como os principais produtores os estados da Bahia, São Paulo e Rio Grande do Sul (IBGE, 2006).

Para suprir esta demanda, os produtores brasileiros vêm investindo em novas tecnologias a fim de aumentar a produtividade e qualidade dos produtos, como, por exemplo, a utilização da cobertura de agrotêxtil que, além de aumentar a produtividade, vem sendo uma alternativa na redução no número de aplicações de agroquímicos, por permitir que a cultura permaneça sem contato com o meio externo, durante parte do seu ciclo.

O agrotêxtil, também chamado de "não tecido", é confeccionado a partir de longos filamentos de polipropileno que são colocados em camadas e soldados

\footnotetext{
${ }^{1}$ Extraído da tese do primeiro autor.

${ }^{2}$ Doutora - Depatamento de Ciências Vegetais/DCV - Universidade Federal Rural do Semi-Árido/UFERSA - Br 110, Km 47 - Presidente Costa e Silva Cx. P. 137 - 59625-900 - Mossoró, RN - evmbio@gmail.com

${ }^{3}$ Mestre - Depatamento de Ciências Vegetais/DCV - Universidade Federal Rural do Semi-Árido/UFERSA - Br 110, Km 47 - Presidente Costa e Silva Cx. P. 137 - 59625-900 - Mossoró, RN - ernildo serafim@yahoo.com.br

${ }^{4}$ Doutores, Professores Adjunto - Depatamento de Ciências Vegetais/DCV - Universidade Federal Rural do Semi-Árido/UFERSA - Br 110, Km 47 Presidente Costa e Silva - Cx. P. 137 - 59625-900 - Mossoró, RN - leilson@ufersa.edu.br; zuleide@ufersa.edu.br; jrrui@hotmail.com ${ }^{5}$ Doutor, Professor Adjunto - Departamento de Ciências Animais/DCA - Universidade Federal Rural do Semi-Árido/UFERSA - Br 110, Km 47 Presidente Costa e Silva - Cx. P. 137 - 59625-900 - Mossoró, RN
} 
entre si por temperaturas apropriadas, constituindo-se num material muito leve e de resistência suficiente para sua utilização na agricultura, permitindo a troca gasosa entre o ambiente externo e o ambiente interno e a passagem de água (ABINT, 2005), além do material agir como uma barreira contra pragas, cria um microclima favorável ao crescimento e desenvolvimento das culturas (HERNÁNDEZ \& CASTILLA, 1993).

Na região Nordeste, mais especificamente no pólo agrícola Mossoró/Assu, o agrotêxtil já é utilizado há, aproximadamente, cinco anos nas culturas do meloeiro e da melancieira, sobre as plantas após o transplantio, até o início da floração, com o objetivo de reduzir a incidência de pragas (principalmente mosca-branca e minadora), entretanto, em algumas cultivares tem-se verificado também que ocorre um aumento do teor de sólidos solúveis totais. Essa proteção evita, conseqüentemente, a entrada de algumas viroses nos primeiros 30 dias de ciclo da cultura, principalmente aquelas transmitidas por mosca-branca e pulgões.

A utilização de tecnologias como a implantação de "Mulch", somada a outras práticas culturais como: introdução de novos híbridos, transplantio, irrigação de alta freqüência, incremento na densidade de plantio, ausência de rotações de cultura adequadas, nem sempre são as mais adequadas para obtenção de uma boa produtividade, pois pode gerar um ambiente favorável ao desenvolvimento de alguns fitopatógenos que vivem no solo, tais como M. cannonballus (BRUTON, 1998).

Esse fungo é um importante patógeno radicular, sendo um dos principais responsáveis pelo colapso do meloeiro e melancieira, em regiões áridas e semi-áridas, em todo mundo (MARTYN \& MILLER, 1996; STANGUELLINI et al., 2003).

No Brasil, o primeiro relato foi verificado em cultivos comerciais de meloeiro no Rio Grande do Norte, onde $M$. cannonballus apresentou índice de freqüência de $15 \%$, em dois campos de produção comercial de melão no verão de 2002 (SALES JÚNIOR et al., 2003).

Acreditava-se que a introdução do referido patógeno tinha sido feita por materiais de propagação contaminados, vindos da Espanha, onde $M$. cannonballus é um fator limitante da produção de meloeiro. Entretanto, em estudos de prospecção da densidade populacional de ascósporos, em solos do Rio Grande do Norte e Ceará, esse fungo foi identificado também em ambiente de ecossistema de Caatinga, não sendo, portanto, introduzido (MEDEIROS, 2005). Da mesma forma, outros estudos sobre a biologia de $M$. cannonballus demonstraram que ele é um habitante natural de solos (STANGUELLINI et al., 1996).
É considerado um fungo termófilo, uma vez que é favorecido por condições de altas temperaturas, entre 25 e $35^{\circ} \mathrm{C}$ (PIVONIA et al., 1997; WOLF, 1996).

Os inóculos primários responsáveis pela infecção são os ascósporos que são produzidos em peritécios de raízes infectadas, apresentam peritécios globosos, pretos, com ascas clavadas a piriformes, contendo apenas um ascósporo por asca. Portanto, o gerenciamento da doença causada por ele pode ser realizado pela detecção e quantificação dos ascósporos no solo por extração física, pelo método flotação em sacarose (SALES JÚNIOR et al., 2006).

Heo et al. (2001) fazendo um levantamento da densidade populacional de solos cultivados com diversas cucurbitáceas, observou que, em solos cultivados com melancia, apresentaram 0,26 ascósporos $\mathrm{g}^{-1}$ de solos provenientes de Ichom, enquanto que em Kwangju, 0,27 ascósporos $\mathrm{g}^{-1}$, ambos na Coréia. Esses autores também fizeram a distribuição vertical dos níveis de ascósporos para as mesmas curcurbitáceas, mostrando que, a $10 \mathrm{~cm}$ de profundidade, havia 0,38 ascósporos $\mathrm{g}^{-1}$ de solo cultivado com melancia enquanto que a 20 e a $30 \mathrm{~cm}$ de profundidade, apresentava 0,1 e 0,3 , respectivamente.

Como não há relatos sobre a influência do agrotêxtil, diante da densidade populacional de patógenos no solo, somado ao fato dessa tecnologia estar ganhando importância no setor agrícola, principalmente na cultura do melão e melancia, objetivou-se, esse trabalho, avaliar a influência do uso do agrotêxtil sobre a densidade populacional de $M$. cannonballus, em solo cultivado com melancia.

\section{MATERIAL E MÉTODOS}

O experimento foi realizado na horta do Departamento de Ciências Vegetais da Universidade Federal Rural do Semi-Árido em Mossoró-RN, no período de agosto a dezembro de 2005, em solo classificado como Argissolo Vermelho-amarelo Eutrófico (EMBRAPA, 1997). Da área experimental, foram retiradas amostras de solo cuja análise química revelou os seguintes resultados: $\mathrm{pH}$ (água1:2,5) = 8,2; $\mathrm{Ca}=4,35 \mathrm{cmolc} \mathrm{dm}^{-3} ; \mathrm{Mg}=0,7 \mathrm{cmolc} \mathrm{dm}^{-3} ; \mathrm{K}=0,41$ cmolc dm dm $^{-3} \mathrm{Al}=0,0 \mathrm{cmolc} \mathrm{dm}^{-3} ; \mathrm{Na}=0,22 \mathrm{cmolc} \mathrm{dm}^{-3}$ e $\mathrm{P}=$ $119,98 \mathrm{mg} \cdot \mathrm{dm}^{-3}$.

O município de Mossoró está situado a $18 \mathrm{~m}$ de altitude, a $5^{\circ} 11^{\prime}$ de latitude sul e $37^{\circ} 20^{\prime}$ 'de longitude oeste. O clima da região, segundo a classificação de Köppen, é BSwh', isto é, seco e muito quente, com duas estações climáticas: uma seca, que vai geralmente de junho a janeiro, e outra chuvosa, de fevereiro a maio, apresentando temperatura média anual de $27,4^{\circ} \mathrm{C}$, precipitação pluviométrica anual irregular com média de $673 \mathrm{~mm}$ e umidade relativa de 68,9\% (CARMO FILHO et al., 1991). 
O delineamento experimental foi em blocos casualizados, em esquema de parcelas subdivididas $(2 \mathrm{x}$ 5), com três repetições. As parcelas foram constituídas por utilização ou não do agrotêxtil (branco com gramatura de $15 \mathrm{~g} \mathrm{~m}^{-2}$ ) e as subparcelas, pelas épocas de coleta de solo $(0,12,24,36,48$ dias após o transplantio - DAT). A parcela experimental foi composta por três fileiras de $15 \mathrm{~m}$ de comprimento, no espaçamento de $2,0 \times 0,5 \mathrm{~m}$, perfazendo uma área de $90 \mathrm{~m}^{2}$ e área total de $540 \mathrm{~m}^{2}$.

O preparo do solo constou de aração e gradagem, seguido do sulcamento em linhas, espaçadas de $2 \mathrm{~m}$ e profundidade de $0,30 \mathrm{~m}$. As adubações foram realizadas com base na análise do solo, sendo aplicado em fundação $4 \mathrm{t} \mathrm{ha}^{-1}$ do composto orgânico polifértil@ ${ }^{\circledR}$ A adubação de cobertura foi realizada diariamente, via água de irrigação com $91 \mathrm{~kg} \mathrm{ha}^{-1}$ de $\mathrm{N}$, na forma de uréia, ácido nítrico e nitrato de cálcio e $126 \mathrm{~kg} \mathrm{ha}^{-1}$ de $\mathrm{K}_{2} \mathrm{O}$ na forma de cloreto de potássio e sulfato de potássio, iniciada a partir do quinto dia após o transplantio. O sistema de irrigação adotado foi por gotejamento, constituído de uma linha lateral por fileira de plantas, com gotejadores tipo autocompensante, com vazão média de $1,4 \mathrm{~L} \mathrm{~h}^{-1}$, espaçados de $0,30 \mathrm{~m}$ e distância entre linhas de $2 \mathrm{~m}$ com irrigações realizadas diariamente, e as lâminas determinadas com base na evapotranspiração da cultura (ALLEN et al., 1998).

A semeadura foi realizada em bandejas de poliestireno expandido para 128 mudas, preenchidas com substrato comercial. O transplantio foi realizado aos 12 dias após a semeadura, quando as mudas apresentavam duas folhas definitivas, no espaçamento 2,0 x 0,5 m. A cultivar utilizada foi a Mickylee, com ciclo em torno de 60 a 80 dias. Após o transplantio, nos tratamentos com agrotêxtil, as plantas foram cobertas e permaneceram por um período de 24 dias (quando teve início o florescimento da melancia). Como tratos culturais foram realizadas capinas manuais e aplicação de defensivos de acordo com as recomendações técnicas adotadas na região, para a melancieira.

Para análise da densidade de ascósporos de $M$. cannonballus, foram coletadas amostras de solo em um esquema de amostragem aleatória simples em cada bloco. As amostras foram compostas por cinco amostras simples, coletadas em ziguezague, numa profundidade de 10 a 20 $\mathrm{cm}$, onde se encontra a maior parte dos ascósporos de $M$. cannonballus (MERTELY et al., 1993). As amostras foram secas em ambiente fechado e depois peneiradas em malha de $2 \mathrm{~mm}$, afim de que fossem retirados os resíduos. Em cada época de coleta, foram retiradas seis subamostras, constituindo as repetições. A extração de ascósporos de M. cannonballus foi realizada pelo método de flotação em sacarose (BELTRÁN et al., 2005).
As amostras foram peneiradas em uma malha de $250 \mu \mathrm{m}$, eliminando-se as partículas retidas. Posteriormente, $20 \mathrm{~g}$ de solo peneirado foram colocadas em $500 \mathrm{~mL}$ de água e agitados durante 5 minutos. Em seguida, passadas por peneiras com malhas de 75 e $30 \mu \mathrm{m}$. As partículas retidas na malha de $30 \mu \mathrm{m}$ foram lavadas em água corrente e centrifugadas à $900 \mathrm{~g}$, durante $4 \mathrm{~min}$. $\mathrm{O}$ sobrenadante foi descartado e as partículas dissolvidas em $40 \mathrm{~mL}$ de solução de sacarose à $50 \%$ e centrifugada à $900 \mathrm{~g}$, durante $2 \mathrm{~min}$. As partículas restantes foram novamente dissolvidas em sacarose $50 \%$ e centrifugadas. Passou-se o sobrenadante por uma malha de $30 \mu \mathrm{m}$ e as partículas retidas foram distribuídas em placas de Pétri, procedendo-se à contagem dos ascósporos característicos em microscópio estereoscópio a 60x.

Durante o ciclo da cultura, para o acompanhamento de alguns fatores microclimáticos, foi instalada uma miniestação metereológica equipada com dataloggers, conectado a sensores de temperatura solo $(15 \mathrm{~cm}$ de profundidade), temperatura do ar (15 $\mathrm{cm}$ acima da superfície do solo) nas áreas com e sem agrotêxtil.

Os dados dos níveis populacionais de ascósporos de M.cannonballus foram transformados em $\sqrt{ } \mathrm{x}+1$. Os dados foram submetidos à análise de variância e as médias comparadas pelo teste de Tukey, ao nível de $5 \%$ de probabilidade e com as médias foram selecionadas curvas de regressões, tendo as épocas de coleta do solo como variável independente. Modelos exponencial, logarítimo, quadrático e polimoniais foram testados, tendo sido selecionados com base no coeficiente de determinação $\left(\mathrm{R}^{2}\right)$ e no quadrado médio do resíduo (QMR).

Visando comparar os valores dos níveis de ascóporos de $M$. cannonballus com as demais variáveis avaliadas, foi efetuada análise de correlação de Pearson, ao nível de $5 \%$ de probabilidade.

\section{RESULTADOS E DISCUSSÃO}

Foram observados níveis de ascósporos de $M$. cannonballus no solo estudado, antes mesmo de ser instalado o experimento, na primeira coleta. Não houve interação significativa entre os fatores estudados. Os tratamentos com e sem cobertura com agrotêxtil não influenciaram significativamente na densidade populacional de $M$. cannonballus.

Modelos polinomiais foram os que melhor se ajustaram para descrever a variação sofrida pela densidade de ascósporos nos períodos analisados, apresentando pontos de máximo de 1,65 ascósporos. $\mathrm{g}^{-1}$ de solo, para o tratamento com cobertura e 1,68 ascósporos. $\mathrm{g}^{-1} \mathrm{de}$ solo, para o tratamento sem cobertura (Figura 1 a e b). 
Com cobertura

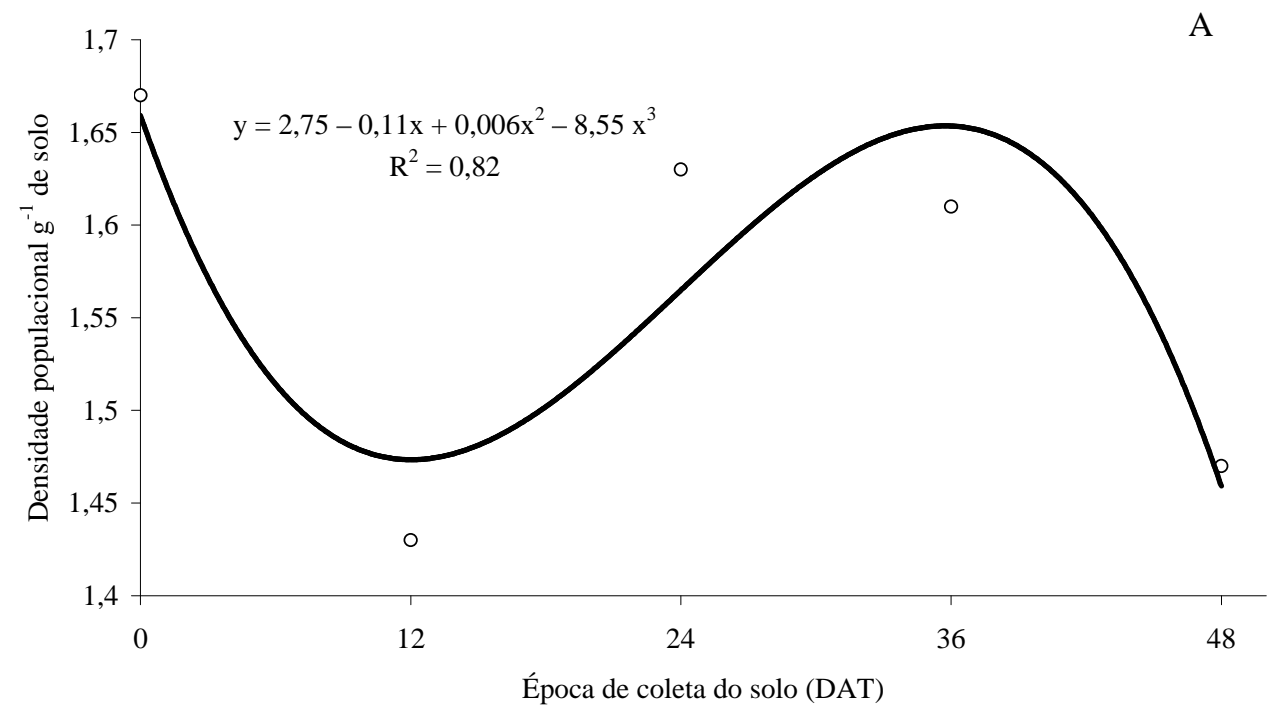

Sem cobertura

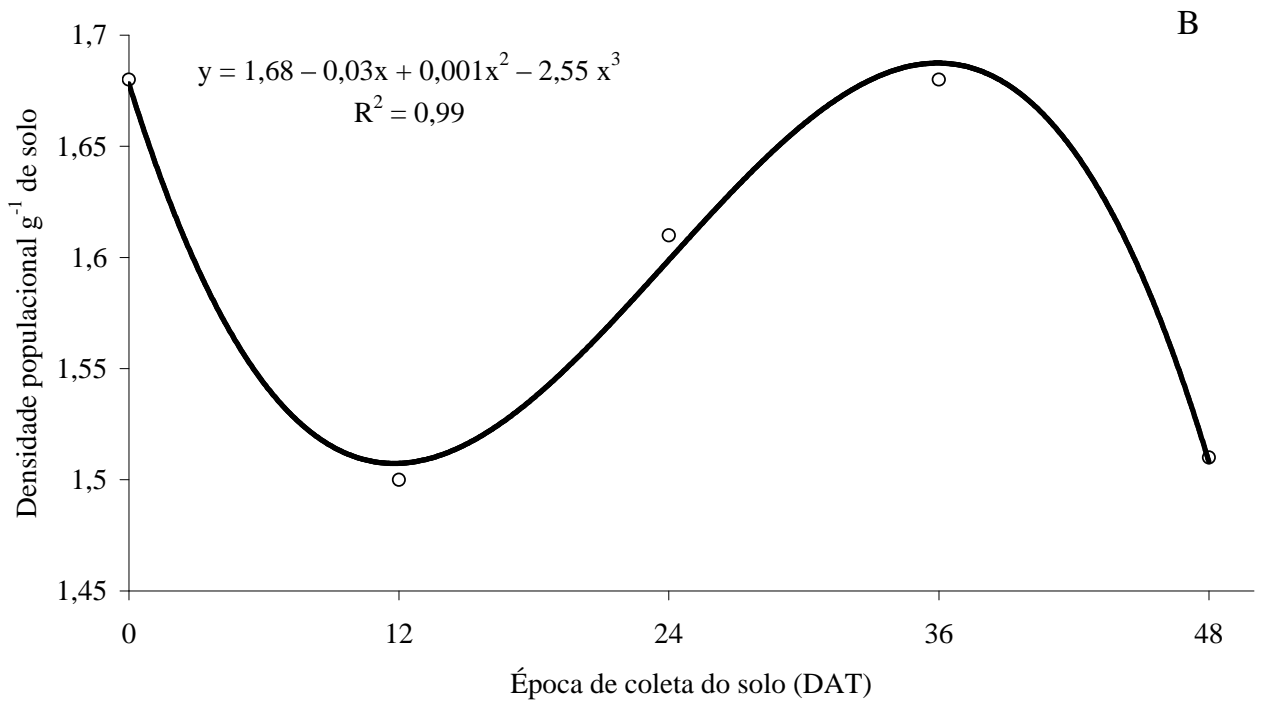

Figura 1 - Densidade populacional de ascósporos de Monosporascus cannonballus $\left(\mathrm{g}^{-1}\right.$ solo $)$ em função dos dias após o transplantio. (a) solo com cobertura de agrotêxtil branco com gramatura de $15 \mathrm{~g} \mathrm{~m}^{-2} \mathrm{e}$ (b) sem cobertura em solo cultivado com melancia Mickylee. UFERSA, Mossoró/RN, 2005.

$\mathrm{Na}$ época em que a cultura esteve protegida, ou seja, 24 dias após o transplantio, os níveis populacionais de ascósporos de $M$. cannonballus apresentaram médias de 1,56 ascósporos. $\mathrm{g}^{-1}$ de solo, para o tratamento com cobertura e de 1,60 ascósporos. $\mathrm{g}^{-1}$ de solo, para o tratamento sem cobertura.
Já após a retirada da cobertura, para o tratamento que estava coberto, a densidade média de ascósporos $\mathrm{g}^{-1}$ de solo na última coleta foi de 1,4 e de 1,5 para o tratamento sem agrotêxtil.

No Brasil, ainda não existe um parâmetro que indique um limiar de risco do número de ascósporos 
necessários para causar doença. Waugh et al. (2003) concluíram que, campos cultivados com meloeiro, eram considerados problemáticos quando apresentavam no mínimo 2 ascósporos. $\mathrm{g}^{-1}$ de solo. Caso esse risco fosse considerado, esse solo estaria no limiar de risco, uma vez que apareceram níveis pouco inferiores à média proposta, porém sem ocorrência de sintomas, podendo vir a ser patogênico e apresentar sintomas de doenças em cultivos sucessivos.

Entretanto, pouco se sabe sobre qual o fator responsável pelo aumento da infectividade e virulência desses ascósporos. Em estudo de prospecção de áreas cultivadas com meloeiro com e sem histórico da doença no Rio Grande do Norte e Ceará, áreas que apresentam histórico de colapso, ocasionado por M. cannonallus, apresentaram médias de 7,94 ascósporos. $\mathrm{g}^{-1}$ de solo, enquanto que áreas sem histórico de colapso, apresentaram níveis significativamente inferiores, com média de 2,17 ascósporos.g-1 de solo (MEDEIROS et al., 2006). Entretanto, a densidade de inóculo inicial é um dos fatores que deve estar associado com outros que a favoreçam, uma vez que, experimentos realizados por Stanguellini et al. (1996), observaram que a densidades populacional de M. cannonballus, em solos de plantio comercial de meloeiro que estavam sendo afetados, era similar à densidade em solos nativos, indicando que existe algum fator que predisponha à infecção.

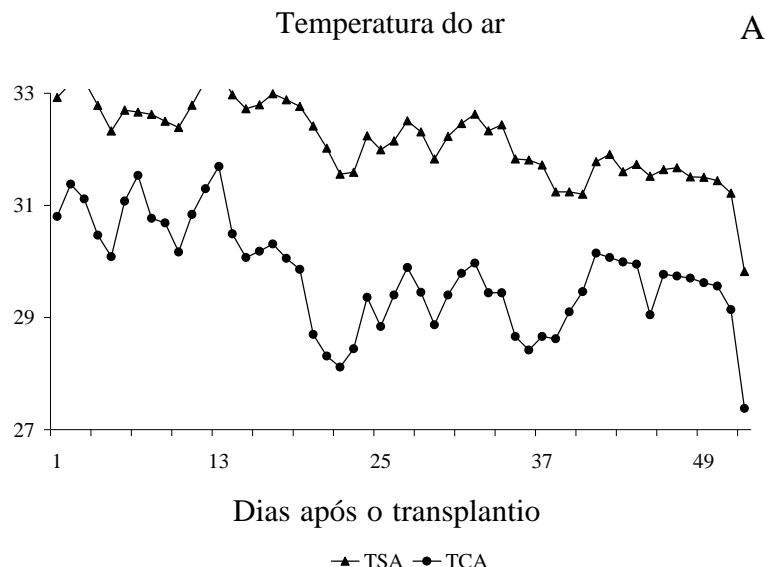

Neste experimento, os solos cultivados com melancieira sob proteção de agrotêxtil apresentaram níveis ascósporos e o referido fungo foi identificado, em associação com outros patógenos, em isolamento realizado em meio de cultura batata dextrose-ágar. Entretanto, não foram observados sintomas de colapso na planta, o que pode ser explicado pelo fato de que a melancia é pouco susceptível ao $M$. cannonballus, como foi observado por Sales Júnior et al. (2002) que obteve um índice geral de doença ocasionado por $M$. cannonballus de 4,4 a 2,2 dentre 19 cultivares de melão, enquanto que nas cultivares de melancia Charleston Gray e Crimson Sweet obtiveram média de índice geral de doença de 1,1 e 1,3 , respectivamente, com porcentagem de reisolamento abaixo de $40 \%$.

O nível de ascósporos não se correlacionou significativamente com a temperatura do solo e do ar em ambos os tratamentos, com e sem cobertura. No período em que a cultura da melancia permaneceu coberta, ou seja, até 24 dias após o transplantio, a diferença máxima da temperatura média diária do ar, entre os dois ambientes foi de $5,32^{\circ} \mathrm{C}$, onde a sua temperatura média com agrotêxtil (TCA) foi de $30,24^{\circ} \mathrm{C}$ e sem agrotêxtil (TSA) de $32,65^{\circ} \mathrm{C}$. Após esse período (retirada da cobertura), a diferença máxima da temperatura média do ar, entre os dois tratamentos, foi de $5,25^{\circ} \mathrm{C}$, com 29,34 e $31,76^{\circ} \mathrm{C}$ de média para a TAC e TAS, respectivamente (Figura 2).

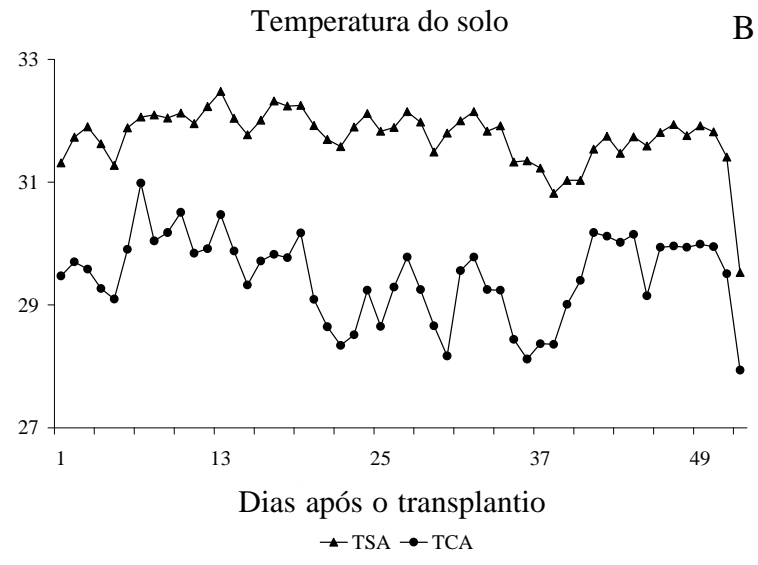

Figura 2 - Média diária da temperatura do ar (a) e do solo (b) com (TCA) e sem (TSA), cobertura de agrotêxtil branco com gramatura de $15 \mathrm{~g} \mathrm{~m}^{-2}$, em função dos dias após o transplantio, ao longo do ciclo da cultura da melancia Mickylee. UFERSA, Mossoró/RN, 2005. 


\section{CONCLUSÕES}

Elevadas densidade de ascósporos de $M$. cannonballus têm sido registradas, em solos com temperaturas, entre 25 e $30^{\circ} \mathrm{C}$ (WAUGH et al., 2003) e sem saturação de umidade (BELTRÁN et al., 2005). Porém, nesse experimento, a diferença máxima da temperatura média do ar e do solo entre os dois tratamentos e entre os períodos analisados (com e sem a cobertura de agrotêxtil), não foi suficiente para provocar diferença significativa $(\mathrm{P}=0,05)$, entre os níveis populacionais de $M$. cannonballus.

Estudos em cultivos sucessivos numa mesma área em que seja adotada a prática da utilização do agrotêxtil são necessários a fim de se verificar o comportamento desse fungo ao longo do tempo, sob proteção da cobertura.

\section{AGRADECIMENTO}

Ao Conselho Nacional de Desenvolvimento Científico e Tecnológico - CNPQ pelo apoio financeiro.

\section{REFERÊNCIAS BIBLIOGRÁFICAS}

ABINT. Agrotêxtil: uma nova alternativa de proteção para a agricultura. Disponível em: <http://www.abint.org/ paginas>. Acesso em: 18 ago. 2005.

ALLEN, R. G.; PEREIRA, L. S.; RAES, D.; SMITH, M. Crop evapotranspiração: guidelines for computing crop water requeriments. Rome: FAO, 1998. 300 p. (Irrigation and drainage paper, 56).

BELTRÁN, R.; VINCENT, A.; SALES JUNIOR, R.; GARCÍA-JIMÉNEZ, J.; ARMENGOL, J. Population dynamics of Monosporascus cannonballus ascospores in marsh soils in eastern Spain. European Journal of Plant Pathology, [S.1.], v. 113, p. 357-365, 2005.

BRUTON, B. D. Soilborne diseases in Cucurbitaceae: pathogen virulence and host resistance. [S.1.]: McCreight, 1998.

CARMO FILHO; ESPÍNOLA SOBRINHO, J. F.; MAIA NETO. Dados metereológicos de Mossoró. Mossoró: ESAM/FGD, 1991. 110 p. (Coleção Mossoroense, série c, 630).

EMPRESA BRASILEIRA DE PESQUISA AGROPECUÁRIA. Manual de métodos de análise de solo. 2. ed. Rio de Janeiro: Centro Nacional de Pesquisa de Solos, 1997. 212 p.

HEO, H.; RYU, K.; LEE, Y. Cultural characteristics and ascospores density in soil of Monosporascus cannonballus on Cucurbitaceae plants. Plant Disease, Quebec, v. 7, p. 16-19, 2001.

HERNANDÉZ, J.; CASTILLA, N. El semiforzado cubiertas flotantes. Hortofruticultura, [S.1.], v. 4, p. 34-36, 1993.

INSTITUTO BRASILEIRO DE GEOGRAFIA E ESTATÍSTICA. IBGE. Disponível em: <http:// www.ibge.gov.br>. Acesso em: 23 out. 2006.

MARTYN, R. D.; MILLER, M. E. Monosporascus root rot and vine decline: an emerging disease of melons worldwide. Plant Disease, Quebec, v. 80, p. 716-725, 1996.

MEDEIROS, E. V. Densidade de ascosporos de Monosporascus cannonballus em solos de Caatinga e de cultivo de meloeiro nos estados do Rio Grande do Norte e Ceará e testes de controle In vitro. 2005. 98 f. Dissertação (Mestrado em Fitotecnia) - Universidade Federal Rural do Semi-árido, Mossoró, 2005.

MEDEIROS, E. V.; SALES JÚNIOR, R.; MICHEREFF, S. J.; BARBOSA, M. R. Quantificação de Ascósporos de Monosporascus cannonballus em Solos não cultivados de Caatinga e em áreas de cultivo de Melão do Rio Grande do Norte e Ceará. Fitopatologia Brasileira, Brasília, 2006. No prelo.

MERTELY, J. C.; MARTYN, R. D.; MILLER, M. E.; BRUTON, B. D. Quantification of Monosporascus cannonballus ascospores in three commercial muskmelon fields in south Texas. Plant Disease, Quebec, v. 77, p. 766771, 1993.

PIVONIA, S.; COHEN, R.; KAFKAFI, U.; BEM,ZE'EV IS; KATAN, J. Sudden wilt of melons in southern Israel: fungal agents and relationship with plant development. Plant Disease, Quebec, v. 81, p. 1264-1268, 1997.

SALES JÚNIOR, R.; BELTRÁN, R.; MICHEREFF, S. J.; ARMENGOL, J.; GARCÍA-JIMÉNEZ, J.; MEDEIROS, E. V. Ascosporas de Monosporascus cannonballus en Suelo. Fitopatologia Brasileira, Brasília, v. 31, p. 185-187, 2006.

SALES JÚNIOR, R.; OLIVEIRA, O. F.; SENHOR, R. F.; ALVES, M. Z. Monosporascus cannonballus agente causal do colapso em plantas de melão no Rio Grande do Norte. Fitopatologia brasileira, Brasília, v. 28, n. 5, p. 567, 2003.

SALES JÚNIOR, R.; VICENT, A.; ARMENGOL, J.; GARCIAJIMÉNEZ, J.; KOBORI, R. F. Comportamento de cultivares de meloeiro e melancia inoculados com Acremonium cucurbitacearum e Monosporascus cannonballus. Fitopatologia brasileira, Brasília, v. 27, n. 2, p. 206-210, 2002. 
STANGHELLINI, M. E.; FERRIN, D. M.; KIM, D. H.; WAUGH, M. M.; RADEWALD, K. C.; SIMS, J. J.; OHR, D. C. Application of preplant fumigants via drip irrigation systems for the management of root rot of melons caused by Monosporascus cannonballus. Plant Disease, Quebec, v. 87, n. 10, p. 1176-1178, 2003.

STANGHELLINI, M. E.; KIM, D. H.; RASMUSSEN, S. L. Ascospores of Monosporascus cannonballus: germination and distribution in cultivated and desert soils in Arizona. Phytopathology, Oxford, v. 86, p. 509-514, 1996.
WAUGH, M. M.; KIM, D. H.; FERRIN, D. M.; STANGHELLINI, M. E. Reproductive potential of Monosporascus cannonballus. Plant Disease, Quebec, v. 87, p. 45-50, 2003.

WOLF, D. W. Evaluation of melon germoplasm for resistente to Monosporascus root rot/vine decline symptomexpression in melon (Cucumis melo L.). In: CUCURBITS TOWARD 2000: EUCARPIA MEETING ON CUCURBIT GENETCS AND BREEDING, 6., 1996, Málaga, Espanha. Resumos... Málaga: [s.n.], 1996. p. 224-228. 